\title{
Power Flow Control in Power System Using FACT Device Thyristor Controlled Series Capacitor (TCSC)
}

\author{
Priyanka Kathal ${ }^{1}$, Arti Bhandakkar ${ }^{2}$ \\ ${ }^{I} M$. Tech IV Semester (Power System) Department of Electrical and Electronics Engineering \\ S.R.I.T Jabalpur, R.G.P.V University-Bhopal, India \\ ${ }^{2}$ Associate Professor, Department of Electrical and Electronics Engineering S.R.I.T Jabalpur, R.G.P.V \\ University-Bhopal, India
}

\begin{abstract}
In modern days due to the ever increasing demand for power in expansion of transmission network, the transmission line are to be operated under loaded condition and there is a risk of power flow control and voltage instability. This paper proposes power flow control in a power system network by incorporating TCSC and SVC devices. The TCSC is a series compensated device to reduce the transmission line reactance in order to improve power flow through it, while the SVC is a shunt compensated device and they improve the voltage profile. This paper presents a systematic procedure for modeling and simulation using MATLAB/SIMULINK (Simpower System blockset). The optimal location of TCSC and SVC device are considered for power flow control and voltage stability limit. The proposed approach is carried out on two-area four-machine 11-bus test system model and the simulated result are presented to validate the proposed test case system. In this paper performance of TCSC and SVC device is analyzed and compare its simulated result for better power flow control in power system.
\end{abstract}

Keywords: FACTS devices (TCSC, SVC), Two-area 11 bus test system model, MATLAB/SIMULINK, Modelling of SVC and TCSC.

\section{INTRODUCTION}

Today's modern interconnected power system is highly complex in nature. One of the most important requirements during the operation of the electric power system is the reliability and stability. Maintaining stability of such an interconnected multi area power system has become a cumbersome task. As a counter measure against these problems, Flexible AC Transmission System (FACTS) devices were proposed [1]. The technology such as flexible ac transmission system (FACTS), can help to find the solution. Facts devices provide voltage support at critical buses in the system (shunt connected controllers) and regulate power flow in critical lines (with series connected controllers) [2]. The need for these power flow controllers capable of increasing transmission capability and controlling power flows is increasing.[3]

\section{TCSC (THYRISTOR CONTROLLED SERIES CAPACITOR)}

Series Capacitors are installed in series with a transmission line, which means that all the equipment has to be installed on a fully insulated platform. Significant device from the group FACTS is a TCSC, which finds application in solving many problems in the power system. Its properties can increase the power lines transmission capacity and power flow control [4]. TCSC is a FACT device available for application in AC line of voltage up to 500KV. In Figure 1 Shown equivalent circuit of the TCSC model as a capacitance in parallel with a variable inductor. The impedance of TCSC $\left(\mathrm{Z}_{\mathrm{TCSC}}\right)$ is given by [5].

$\mathrm{Z}_{\mathrm{TCSC}}=(-\mathrm{jXc})\left(\mathrm{j} \mathrm{X}_{\mathrm{TCR}}\right) / \mathrm{j}\left(\mathrm{X}_{\mathrm{TCR}}-\mathrm{Xc}\right)$

$\mathrm{Z}_{\mathrm{TCSC}}=(-\mathrm{jXc}) /\left(1-\mathrm{Xc} / \mathrm{X}_{\mathrm{TCR}}\right)$

The current through the TCR ( $\left.\mathrm{I}_{\mathrm{TCSC}}\right)$ is given by

$\mathrm{I}_{\mathrm{TCSC}}=(-\mathrm{jXc}) \mathrm{I}_{\mathrm{L}} / \mathrm{j}\left(\mathrm{X}_{\mathrm{TCR}}-\mathrm{Xc}\right)$

$\mathrm{I}_{\mathrm{TCSC}}=\mathrm{IL} /\left(1-\mathrm{X}_{\mathrm{TCR}} / \mathrm{Xc}\right)$

Since the losses are neglected, the impedance of TCSC is purely reactive [5]. The capacitive reactance of TCSC is obtained from figure 2.

$\mathrm{X}_{\mathrm{TCSC}}=\mathrm{Xc} /\left(1-\mathrm{Xc} / \mathrm{X}_{\mathrm{TCR}}\right)$ 


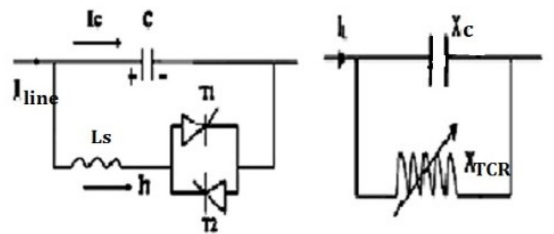

Fig. 1.TCSC and Equivalent circuit of TCSC [5].

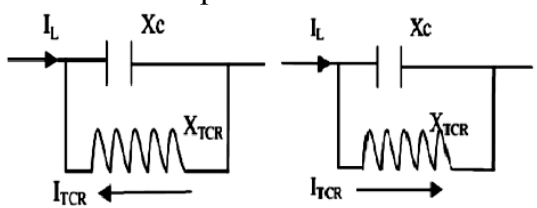

Fig. 2. Capacitive operation and Inductive operation [5].

A TCSC is a series controlled capacitive reactance that can provide continuous control of power on the ac line over a wide range. From the system viewpoint, the principle of variable series compensation is simply to increase the fundamental frequency voltage across a fixed capacitor (FC) in a series compensated line through appropriate variation of the firing angle $(\alpha)$ [6].This enhanced voltage changes the effective value of the seriescapacitive reactance [7]. The TCSC can operate in capacitive or inductive mode, although the latter is rarely used in practice. Since the resonance for this TCSC is around $58^{0}$ firing angle $(\alpha)$. The resonance for the overall system (when the line impedance is included) is around $67^{\circ}$. The impedance is lowest at $90^{\circ}$ and therefore power transfer increases as the firing angle is reduced. In capacitive mode the range for impedance values is approximately $120 \Omega-136 \Omega[8]$.

(1) $\alpha$ for Inductive mode: $\quad 0^{0}-49^{0}$

(2) $\alpha$ for Resonance Region: $49^{\circ}-69^{\circ}$

(3) $\alpha$ for Capacitive mode: $69^{\circ}-90^{\circ}$

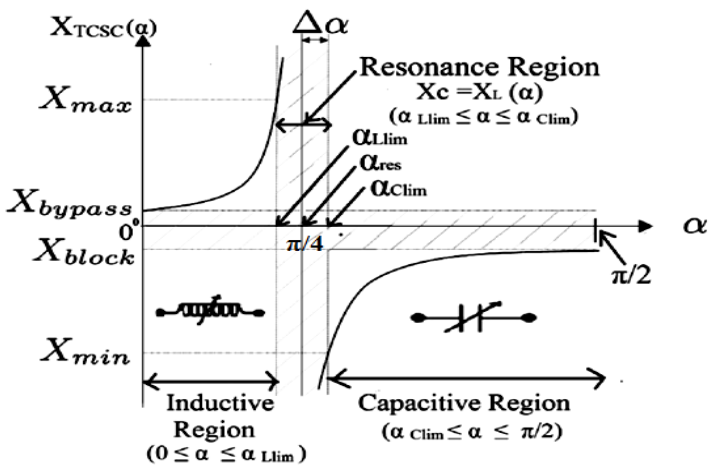

Fig. 3. Operating characteristics of TCSC [9][12]

\section{SVC (STATIC VAR COMPENSATOR)}

SVC can be defined as a shunt connected static var generator or absorber whose output is adjusted to exchange capacitive or inductive current so as to maintain or control specific parameters of the electrical power system (typically bus voltage). SVCs are primarily used in power systems for voltage control or for improving system stability. This is a general term for a thyristor-controlled or thyristor-switched reactor and/or thyristor-switched capacitor or combination use for absorbing reactive power and for supplying the reactive power [10]. The SVC uses conventional thyristors to achieve fast control of shunt-connected capacitors and reactors. The configuration of the SVC is shown in Figure, which basically consists of a fixed capacitor (C) and a thyristor controlled reactor $(\mathrm{L})$. The firing angle control of the thyristor banks determines the equivalent shunt admittance presented to the power system [11]. 


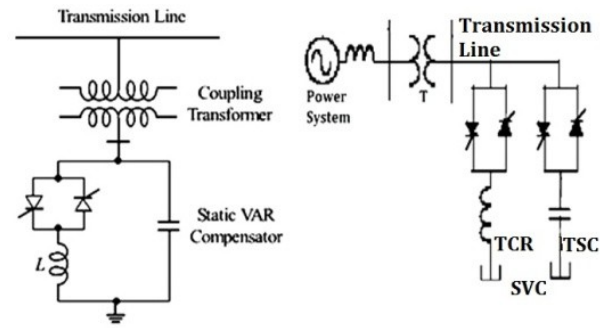

Fig. 4. Different connections of SVC are connected to transmission line [11],[8].

IV. SVC (STATIC VAR COMPENSATOR)

The SVC can be operated in two different modes [8]:

1. In voltage regulation mode (the voltage is regulated within limits as explained below)

2. In var control mode (the SVC susceptance is kept constant)

When the SVC is operated in voltage regulation mode, it implements the following V-I characteristic.

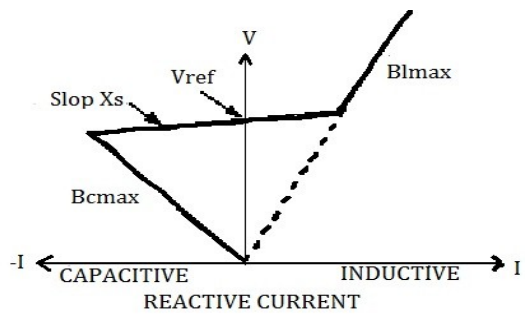

Fig. 5. SVC V-I characteristic [8]

As long as the SVC susceptance B stays within the maximum and minimum susceptance values imposed by the total reactive power of capacitor banks (Bcmax) and reactor banks (Blmax), the voltage is regulated at the reference voltage Vref. However, a voltage droop is normally used (usually between $1 \%$ and $4 \%$ at maximum reactive power output), and the V-I characteristic has the slope indicated in the figure 5. The V-I characteristic is described by the following three equations [8]:

1. If $\mathrm{SVC}$ is in regulation mode $(-\mathrm{Bcmax}<\mathrm{B}<\mathrm{Blmax})$

$$
\mathrm{V}=\mathrm{Vref}+\mathrm{I} \cdot \mathrm{Xs}
$$

2. If SVC is Fully Capacitive ( $\mathrm{B}=\mathrm{Bcmax}$ )

$$
V=\frac{-\mathrm{I}}{\text { Bcmax }}
$$

3. If SVC is Fully Inductive ( $\mathrm{B}=\mathrm{B} \operatorname{lmax}$ )

$$
V=\frac{\mathrm{I}}{\mathrm{Blmax}}
$$

Where,

$\mathrm{V}=$ Positive sequence voltage $(\mathrm{pu})$,

$\mathrm{I}=$ Reactive current (pu/Pbase) $(\mathrm{I}>0$ indicates an inductive current),

$\mathrm{Xs}=$ Slope or droop reactance (pu/Pbase),

Bcmax = Maximum capacitive susceptance (pu/Pbase) with all TSCs in service, no TSR or TCR,

Blmax = Maximum inductive susceptance (pu/Pbase) with all TSRs in service or TCRs at full conduction, no TSC.

\section{Two-Area Test System Model With SvC FaCt DeVICE}

A multi machine power system with 11 bus two areas test system, Area-1 and Area-2 system is used to access the effectiveness of SVC model developed. Figure 6 show the proposed single line diagram of 11 bus power system with installed SVC shunt Fact device has been considered. 


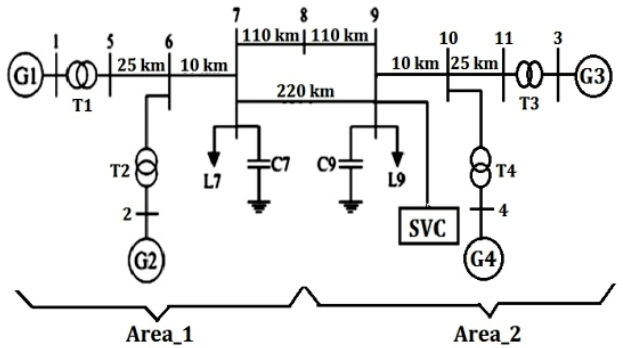

Fig. 6. Two-area Four-machine 11-bus power system with shunt FACT device SVC.

\section{TeSt System Simulation Model Of SvC USing Matlab/SimulinK}

All the relevant parameters are given in Appendix. The source voltages of $13.8 \mathrm{kV}$ are connected by a $290 \mathrm{~km}$ transmission line through three-phase step-up transformers. The system consists of two output voltage of transformer is $500 \mathrm{KV}$ equivalents, respectively 1000MVA and 4200MVA in each area, connected by a $290 \mathrm{~km}$ transmission line. The loads in each area having $30 \mathrm{KW}$ are so chosen that the real power flow on the transmission line from area 1 to 2 . The SVC used for this model is a phasor model is shown in figure 7. The load centre of approximately $60 \mathrm{KW}$ is modelled where the active \& reactive power absorbed by the load is a function of the system voltage.

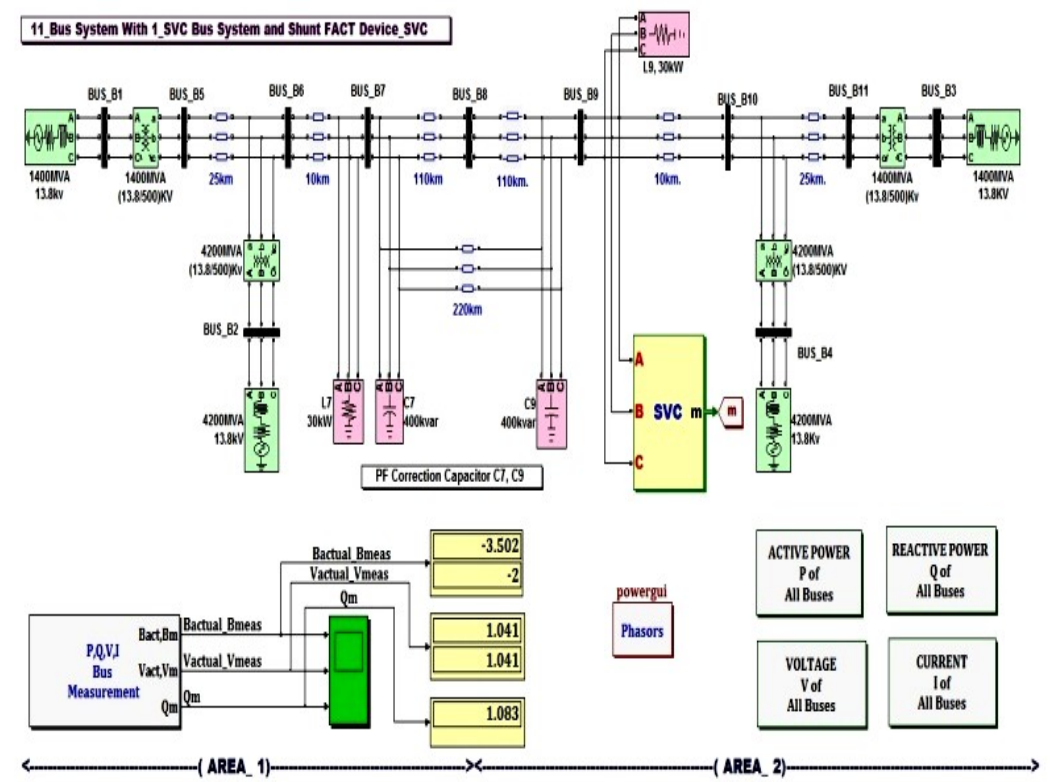

Fig. 7. Simulink model of 11 bus power system with installed SVC at bus 9. (For Voltage regulation mode)

\section{Simulation Results OF SVC}

The SVC control block represent the SVC susceptance, voltage actual and measure value and also shown the measure value of SVC reactive power. The actual quantities trace represent by Magenta colour and measure represent by yellow trace is shown in figure 8. In this paper the SVC is operated in voltage regulation mode only and obtained all the data in this mode is shown in following figures.

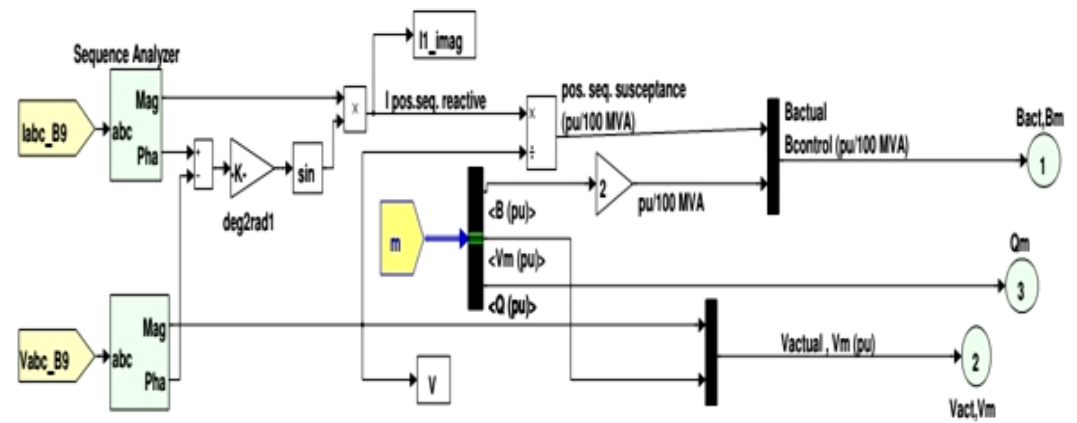

Fig. 8. Control Parameter blocks of SVC FACT device 

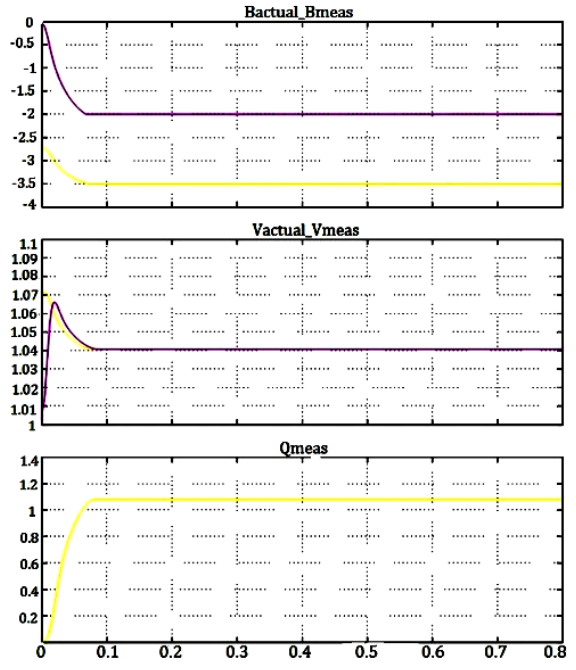

Fig. 9. Variation of SVC measure and Actual value of B, V and Qm

The SVC shunt FACT device installed in 11 bus system to find out the active and reactive power flow in all the buses, the power at bus B1, B2, B3, B4, B5, B6, B7, B8, B9, B10 and at B11 is calculated, the variations in total active reactive power will be shown in figure 10, figure 11, figure 12 and figure 13.

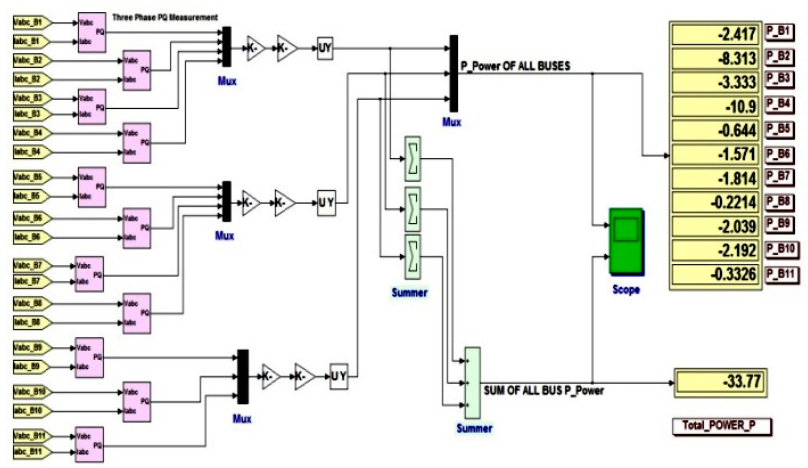

Fig. 10. Block represent Active power (P) of all buses and the sum of total power at buses (with SVC Connected at Bus 9)

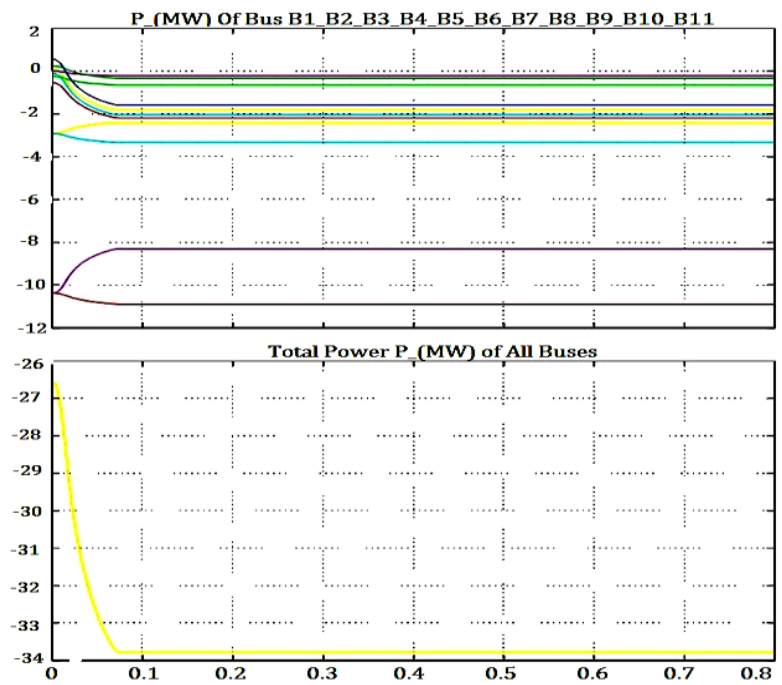

Fig. 11. Active power (P) of all buses and sum of total active power at the buses (with SVC Connections) 


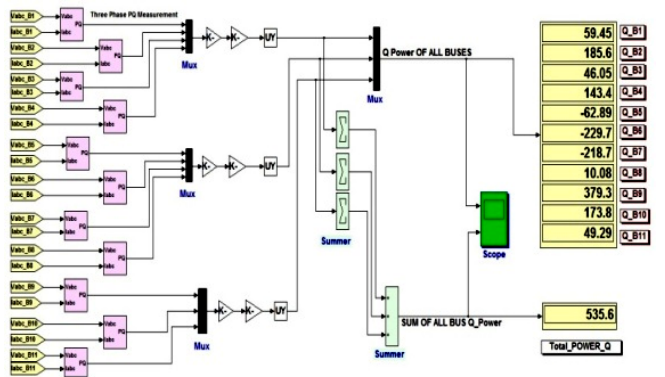

Fig. 12. Block represent Reactive power (Q) of all buses and the sum of total power at buses (with SVC Connected at Bus 9).

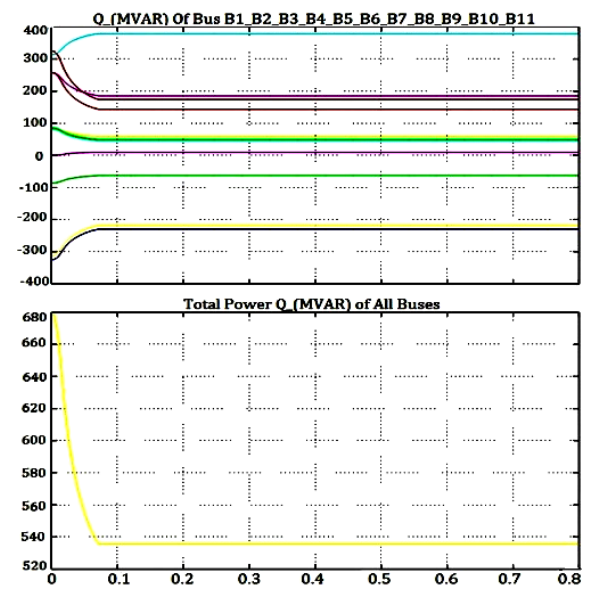

Fig. 13. Reactive power (Q) of all buses and sum of total reactive power at the buses (with SVC Connected at Bus 9).

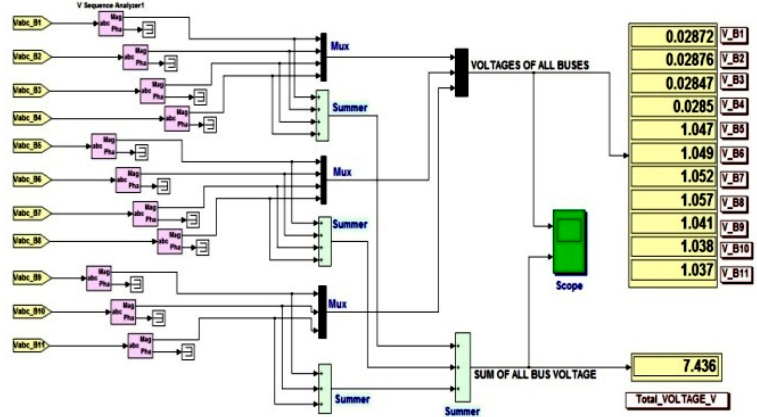

Fig. 14. Block representation of voltage control by SVC Shunt device at different buses and sum of total bus voltage.

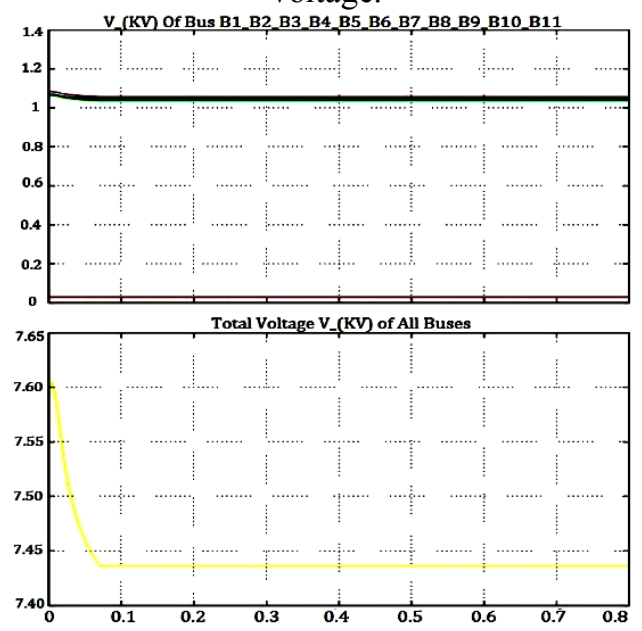

Fig. 15. Graphically represent the bus voltage control by SVC device at different buses and sum of total voltage. 


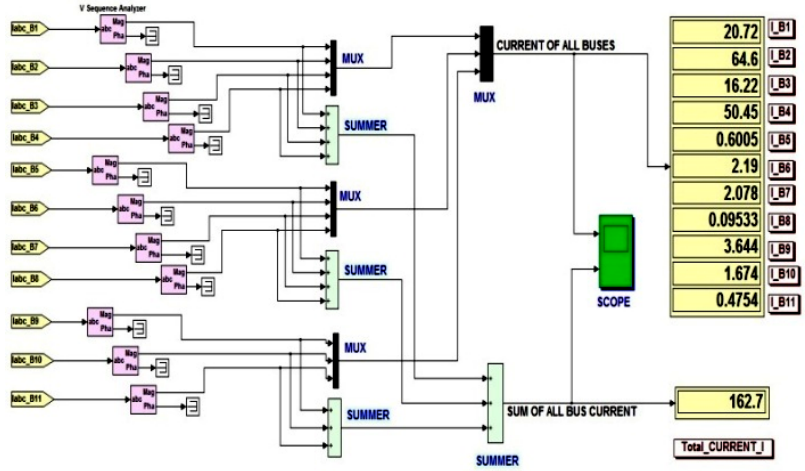

Fig. 16. Block representation of Current by SVC Device at different buses and sum of total bus Current.

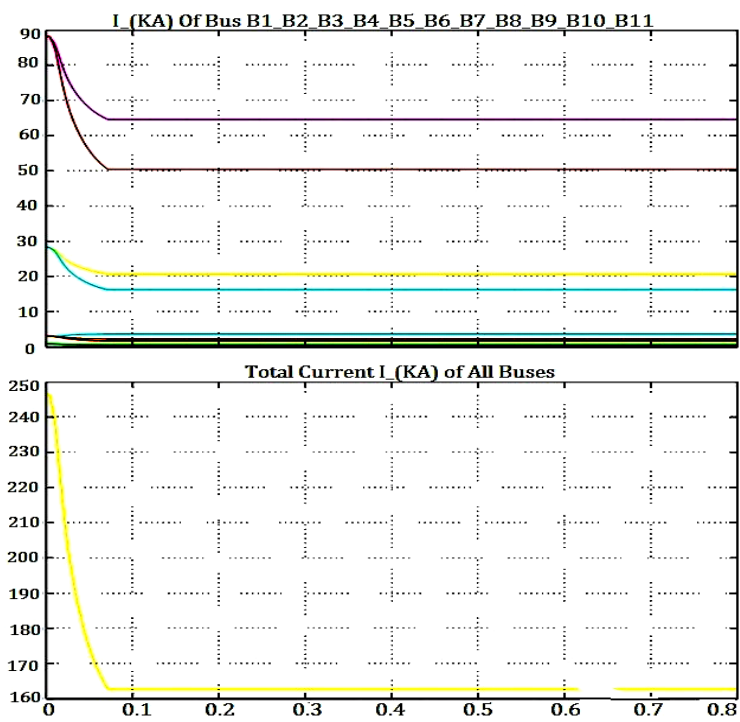

Fig. 17. Graphically represent the bus current by SVC device at different buses and sum of total bus current

\section{Two-AREa TeSt System With TCSC FACT DeVICE}

A multi machine power system with 11 bus two area test system, Area-1 and Area-2 system is used to access the effectiveness of TCSC model developed. Figure 18 show the proposed single line diagram of 11 bus power system with installed TCSC Fact device has been considered. The Series TCSC Fact device is connected between bus 9 and bus 10. The G1, G2, G3, G4 represent the generators and T1, T2, T3, T4 represent the transformers. The power flow in the $290 \mathrm{~km}$ transmission systems is split-up in to two segments having a length of $110 \mathrm{~km}, 25 \mathrm{~km}$ and $10 \mathrm{~km}$ respectively in both areas.

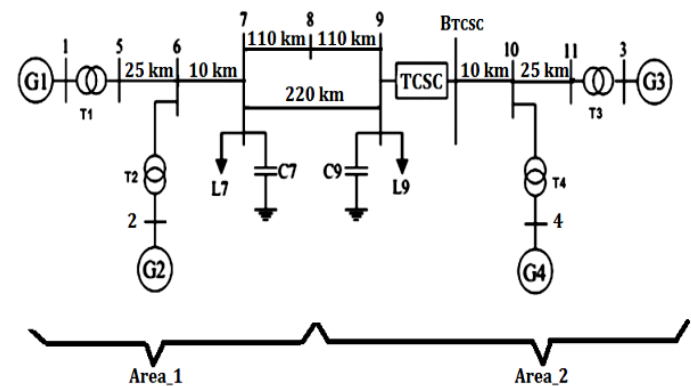

Fig. 18. Two-area Four-machine 11-bus power system with series FACT device TCSC.

\section{Test System Simulation Model OF TCSC USIng Matlab/SimulinK}

All the relevant parameters are given in Appendix. The source voltages of $13.8 \mathrm{kV}$ are connected by a $290 \mathrm{~km}$ transmission line through three-phase step-up transformers. The system consists of two output voltage of transformer is $500 \mathrm{KV}$ equivalents, respectively 1000MVA and 4200MVA in each area, connected by a $290 \mathrm{~km}$ transmission line. The loads in each area having $30 \mathrm{KW}$ are so chosen that the real power flow on the transmission line from area 1 to 2 . The TCSC used for this model is a phasor model. The load centre of 
approximately $60 \mathrm{KW}$ is modelled where the active \& reactive power absorbed by the load is a function of the system voltage.

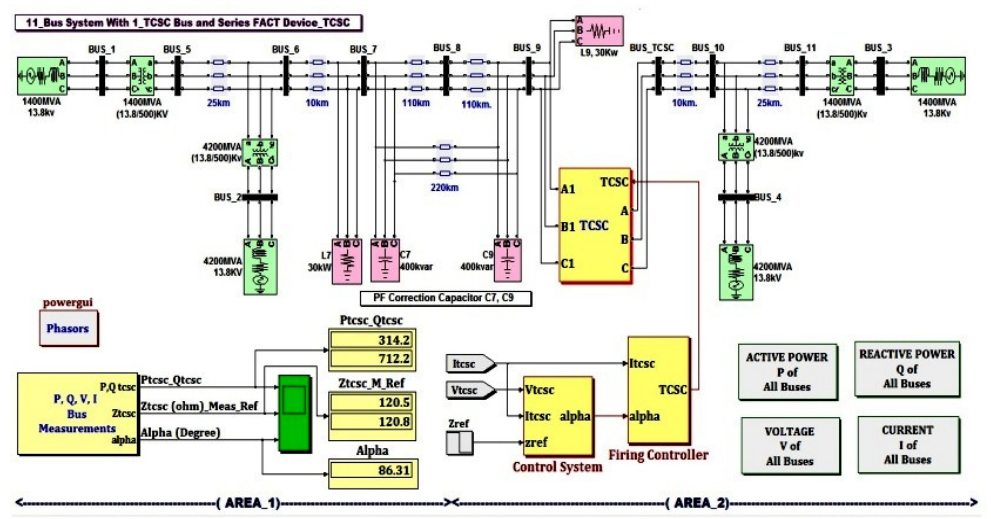

Fig. 19. Simulink model of 11 bus power system with installed TCSC at bus 9. (For capacitive mode only)

\section{Simulation Results Of TCSC}

The TCSC parameter blocks and curve with respect to time is show the TCSC voltage, TCSC current, Active, Reactive power, TCSC impedance and firing angle is illustrate in figure 22. For the first $0.5 \mathrm{~s}$, the TCSC is bypassed, at $0.5 \mathrm{~s}$ TCSC begins to regulate the impedance to $128 \Omega$ and this increases power transfer, the TCSC starts with alpha at $90^{\circ}$ to enable lowest switching disturbance on the line. In this paper the TCSC operate in capacitive mode only and regulate the firing angle $90^{\circ}$ initially from 0 to $0.5 \mathrm{sec}$ after that decrease up to $75.6^{\circ}$ from $0.56 \mathrm{sec}$ to $2.5 \mathrm{sec}$. The capacitive mode start at 2.5 to $5 \mathrm{sec}$ and the firing angle is constant and maintain $86.31^{\circ}$ at this value the impedance of TCSC is measure $120.5 \Omega$ along the reference value $120.8^{0}$ is shown in figure 22.

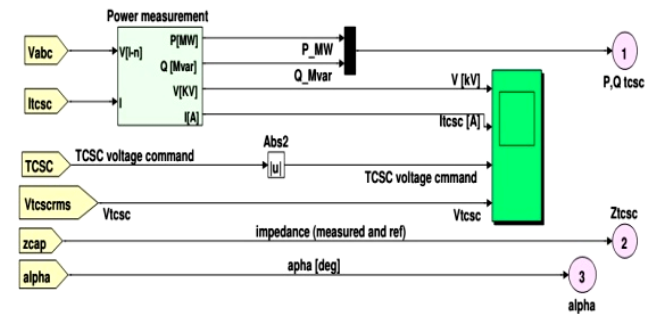

Fig. 20. TCSC parameter blocks.
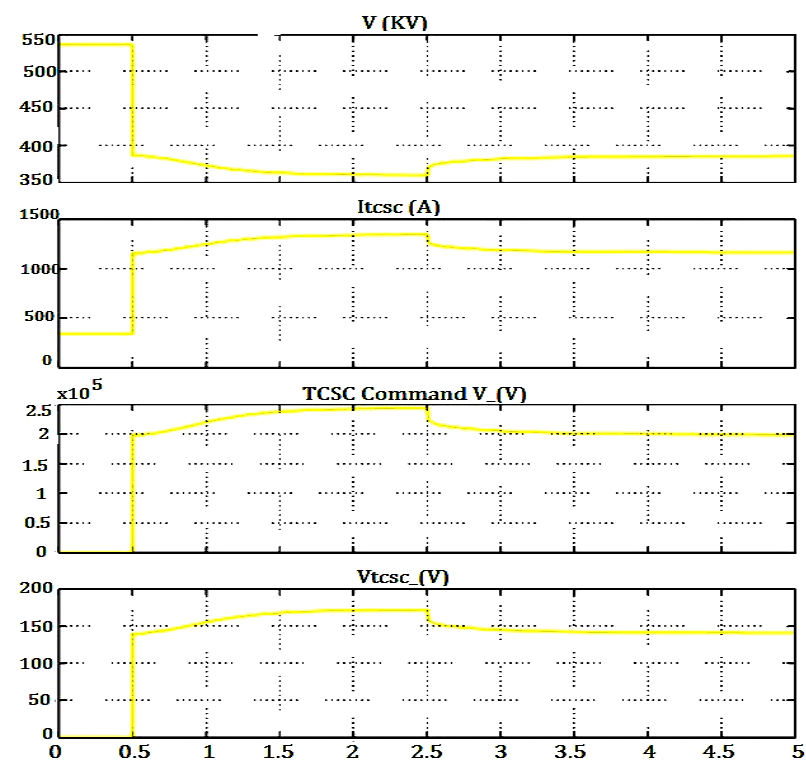

Fig. 21. TCSC control parameters. 

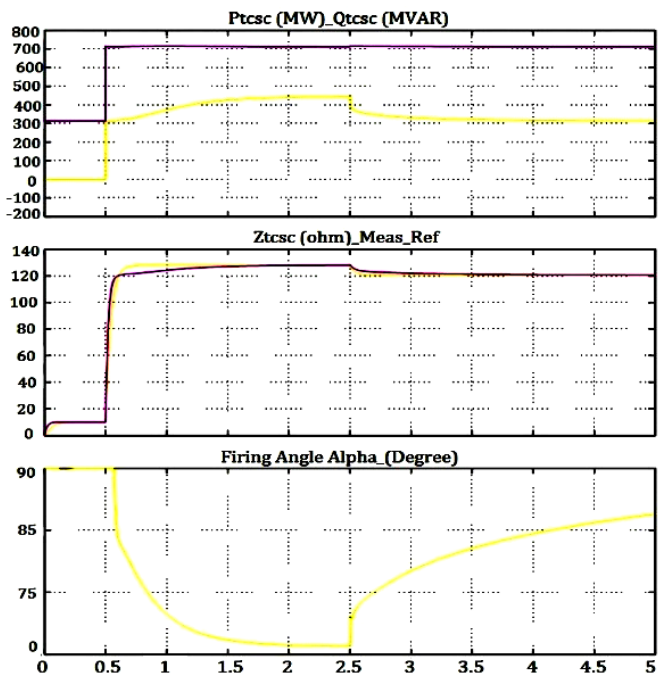

Fig. 22. TCSC injected Active, Reactive Power and TCSC regulates the impedance with respect to firing angle.

The TCSC fact device installed in 11 bus system to find out the active power flow in all the buses, the power at bus $\mathrm{B} 1, \mathrm{~B} 2, \mathrm{~B} 3, \mathrm{~B} 4, \mathrm{~B} 5, \mathrm{~B} 6, \mathrm{~B} 7, \mathrm{~B} 8, \mathrm{~B} 9, \mathrm{~B} 10, \mathrm{~B} 11, \mathrm{Btcsc}$ is calculated and total power will be improved by TCSC is $1730 \mathrm{MW}$ is shown in figure 23 and figure 24 .

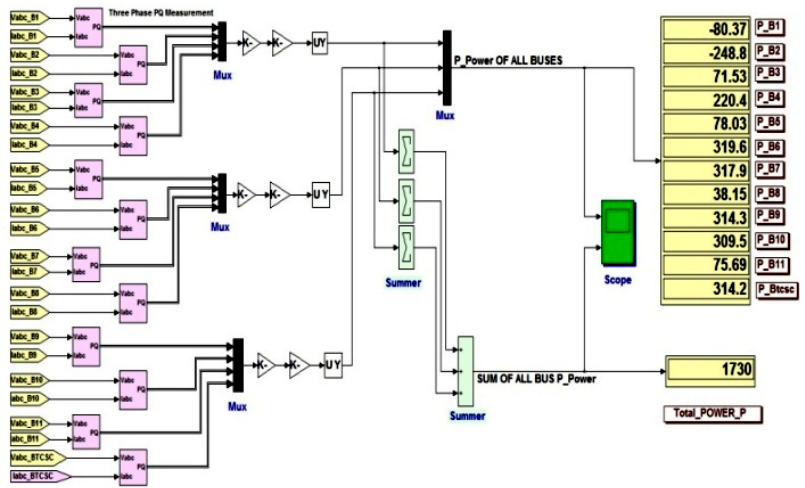

Fig. 23. Block represent Active power (P) of all buses and the sum of total power at buses.

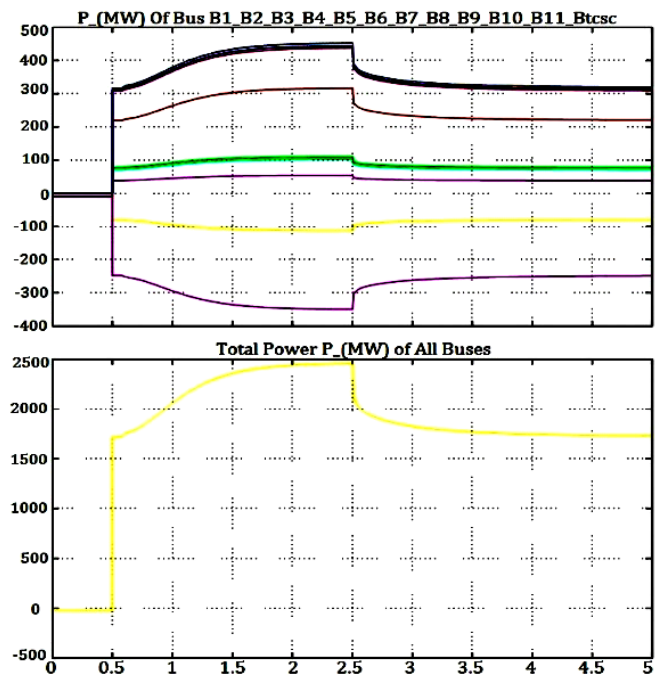

Fig. 24. Active power (P) of all buses and sum of total active power at the buses.

The Reactive power flow control by TCSC at buses, the total power will be improved by TCSC is 5221MVA shown in figure 25 and figure 26. (Block reprentation and graphical output) 


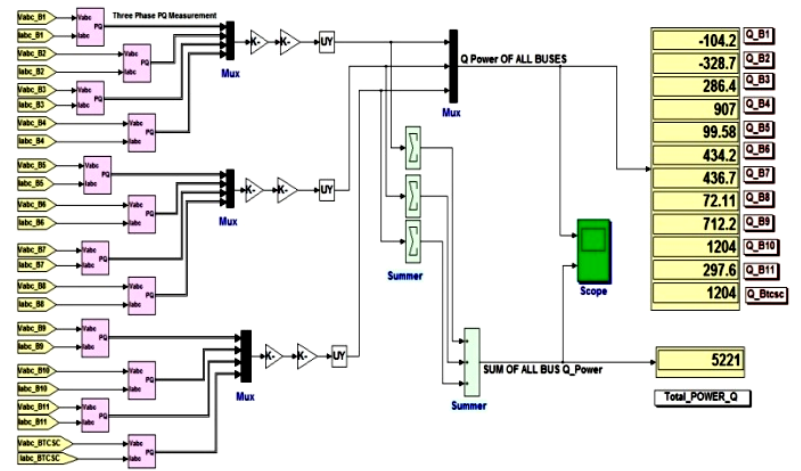

Fig. 25. Block represent Reactive power (Q) of all buses and the sum of total reactive power at all buses.

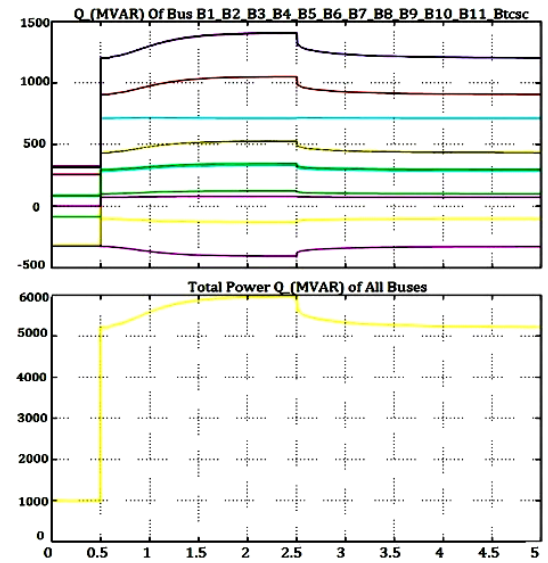

Fig. 26. Reactive power (Q) of all buses and sum of total reactive power at the buses.

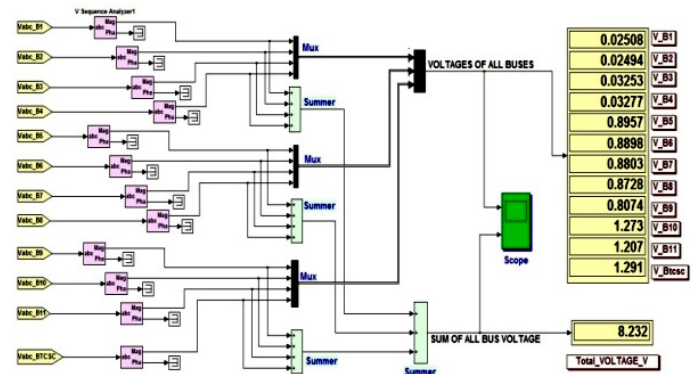

Fig. 27. Block representation of voltage control by TCSC Series FACT device at different buses and sum of total voltage.
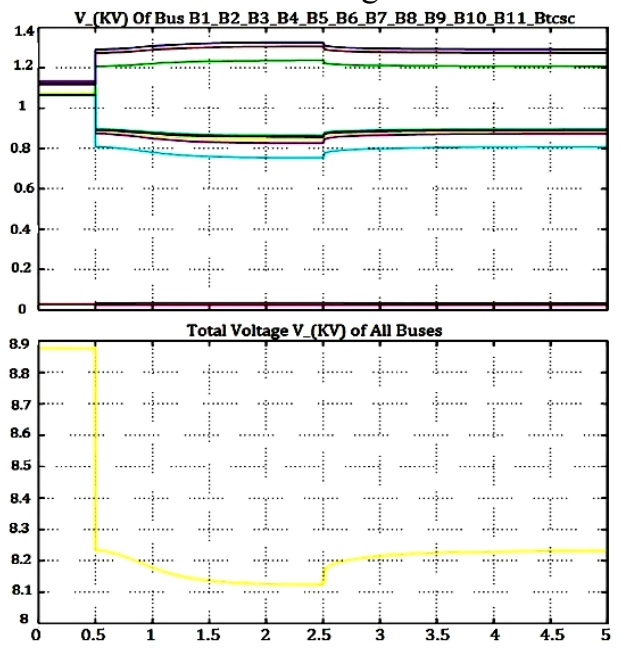

Fig. 28. Graphically represent the bus voltage control by TCSC device at different buses and sum of total voltage. 


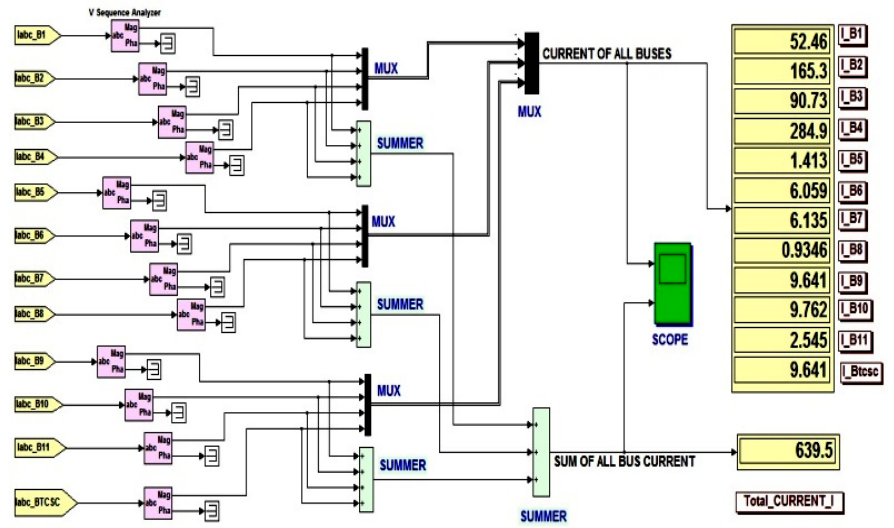

Fig. 29. Block representation of Currents at different buses and sum of total Current.
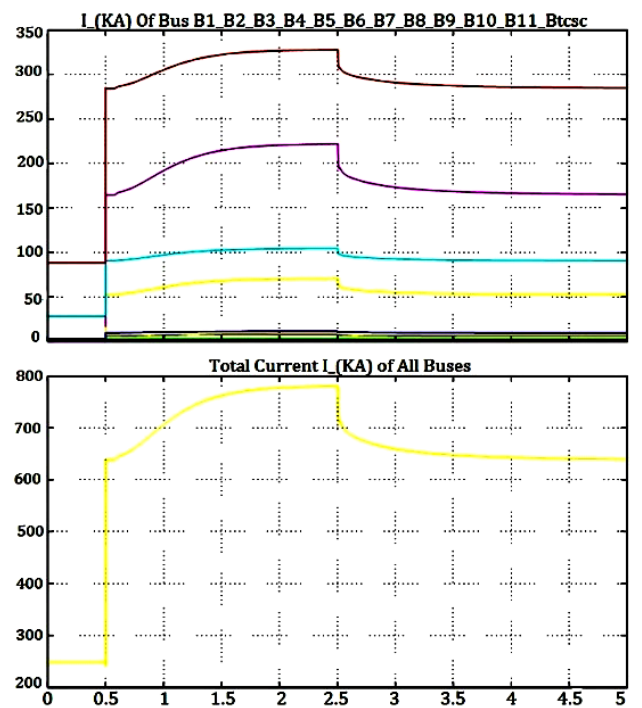

Fig. 30. Graphically represent the bus current at different buses and sum of all bus current.

\section{SUMmary OF Simulated ReSUlts}

The performance of the proposed model are compared and analyzed, by analyzing TCSC can better improved the power flow in transmission line that is active and reactive power $1730.13 \mathrm{MW}, 5221 \mathrm{MVA}$ as compared to SVC $-33.77 \mathrm{MW}, 535.68 \mathrm{MVA}$ also the TCSC increased the transmission line voltage $8.23 \mathrm{kv}$ as compared to SVC device. All the TCSC data obtained for capacitive operation mode only, and SVC data obtain for voltage regulation mode only. According to the result it was observed that in SVC and TCSC controller, the TCSC are more effective in power flow control and voltage control in power system network. The bus data of SVC and TCSC FACT device for Active, Reactive power, Voltage and current at buses is shown in table 1.

Table 1 Comparison between TCSC and SVC for P, Q, V and I at all the buses.

\begin{tabular}{|c|c|c|c|c|c|c|c|c|}
\hline & SvC & TCSC & SvC & TCSC & SVC & TCSC & SvC & TCSC \\
\hline BUSES & $\mathrm{P}(\mathrm{MW})$ & $\mathrm{P}(\mathrm{MW})$ & Q(MVAR) & Q(MVAR) & $\mathrm{v}(\mathrm{KV})$ & $\mathrm{V}(\mathrm{KV})$ & $I(\mathrm{KA})$ & $I(\mathrm{KA})$ \\
\hline B_1 & -2.417 & -80.37 & 59.45 & \begin{tabular}{r|}
104.2 \\
\end{tabular} & 0.02872 & 0.02508 & 20.72 & 52.46 \\
\hline B_2 & -8.313 & -248.8 & 185.6 & -328.7 & 0.02876 & 0.02494 & 64.6 & 165.3 \\
\hline B_3 & -3.333 & 71.53 & 46.05 & 286.4 & 0.02847 & 0.03253 & 16.22 & 90.73 \\
\hline B_4 & \begin{tabular}{|c|}
-10.9 \\
\end{tabular} & 220.4 & 143.4 & 907 & 0.0285 & 0.03277 & 50.45 & 284.9 \\
\hline B_5 & -0.644 & 78.03 & -62.89 & 99.58 & 1.047 & 0.8957 & 0.6005 & 1.413 \\
\hline B_6 & -1.571 & 319.6 & -229.7 & 434.2 & 1.049 & 0.8898 & 2.19 & 6.059 \\
\hline B_7 & -1.814 & 317.9 & -218.7 & 436.7 & 1.052 & 0.8803 & 2.078 & 6.135 \\
\hline B_8 & -0.2214 & $\mathbf{3 8 . 1 5}$ & 10.08 & 72.11 & 1.057 & 0.8728 & 0.09533 & 0.9346 \\
\hline B_9 & -2.039 & 314.3 & 379.3 & 712.2 & 1.041 & 0.8075 & 3.644 & 9.641 \\
\hline B_10 & -2.192 & 309.5 & 173.8 & 1204 & 1.038 & 1.273 & 1.674 & 9.762 \\
\hline B_11 & -0.3326 & 75.69 & 49.29 & 297.6 & 1.037 & 1.207 & 0.4754 & 2.545 \\
\hline Btesc & N.C & 314.2 & N.C & 1204 & N.C & 1.291 & N.C & 9.641 \\
\hline TOTAL & -33.777 & 1730.13 & 535.68 & 5220.89 & 7.43545 & 8.23242 & 162.747 & 639.521 \\
\hline
\end{tabular}

\begin{tabular}{|c|c|}
\hline \multicolumn{2}{|c|}{ TCSC-Data } \\
\hline Ptcsc & $\mathbf{3 1 4 . 2}$ \\
\hline Qtcsc & $\mathbf{7 1 2 . 2}$ \\
\hline Zm & $\mathbf{1 2 0 . 5}$ \\
\hline Zref & $\mathbf{1 2 0 . 8}$ \\
\hline Alpha & $\mathbf{8 6 . 3 1}$ \\
\hline
\end{tabular}

\begin{tabular}{|c|c|}
\hline \multicolumn{2}{|c|}{ SVC-Data } \\
\hline Bactual & $\mathbf{- 3 . 5 0 2}$ \\
\hline Bm & -2 \\
\hline Vactual & 1.041 \\
\hline Vm & 1.041 \\
\hline Qm & 1.083 \\
\hline
\end{tabular}




\section{APPENDIX}

\begin{tabular}{|c|c|c|}
\hline S.No & Name & Parameter \\
\hline \multirow{2}{*}{1} & \multirow[b]{2}{*}{ 3-ø Source } & $V(K V)=13.8 \mathrm{e} 3, \mathrm{f}(\mathrm{Hz})=60, \mathrm{MVA}=1400 \mathrm{e} 6, \mathrm{X} / \mathrm{R}=8$. \\
\hline & & $V(\mathrm{KV})=13.8 \mathrm{e} 3, \mathrm{f}(\mathrm{Hz})=60, \mathrm{MVA}=4200 \mathrm{e} 6, \mathrm{X} / \mathrm{R}=8$ \\
\hline \multirow{2}{*}{2} & \multirow{2}{*}{ 3-ø Transformer } & $\begin{array}{l}\mathrm{Pn}(\mathrm{MVA})=1400 \mathrm{e} 6, \mathrm{f}(\mathrm{Hz})=60, \mathrm{~V} 1 \mathrm{Ph}-\mathrm{Ph}(\mathrm{Vrms})(\mathrm{KV})=13.8 \mathrm{e} 3 \\
\mathrm{R} 1(\mathrm{pu})=0.002, \mathrm{~L} 1(\mathrm{pu})=0.08, \mathrm{~V} 2 \mathrm{Ph}-\mathrm{Ph}(\mathrm{Vrms})(\mathrm{KV})=500 \mathrm{e} 3, \\
\mathrm{R} 2(\mathrm{pu})==0.002, \mathrm{~L} 2(\mathrm{pu})=0.08, \mathrm{Rm}(\mathrm{pu})=500, \mathrm{Lm}(\mathrm{pu})=500 .\end{array}$ \\
\hline & & $\begin{array}{l}\mathrm{Pn}(\mathrm{MVA})=4200 \mathrm{e} 6, \mathrm{f}(\mathrm{Hz})=60, \mathrm{~V} 1 \mathrm{Ph}-\mathrm{Ph}(\mathrm{Vrms})(\mathrm{KV})=13.8 \mathrm{e} 3 \\
\mathrm{R} 1(\mathrm{pu})=0.002, \mathrm{~L} 1(\mathrm{pu})=0.08, \mathrm{~V} 2 \mathrm{Ph}-\mathrm{Ph}(\mathrm{Vrms})(\mathrm{KV})=500 \mathrm{e} 3, \\
\mathrm{R2}(\mathrm{pu})==0.002, \mathrm{~L} 2(\mathrm{pu})=0.08, \mathrm{Rm}(\mathrm{pu})=500, \mathrm{Lm}(\mathrm{pu})=500\end{array}$ \\
\hline \multirow{3}{*}{3} & \multirow{3}{*}{$\begin{array}{l}\text { Distributed } \\
\text { Parameter Line }\end{array}$} & $\begin{array}{l}\mathrm{Km}=10 \& 25, \mathrm{f}(\mathrm{Hz})=60, \mathrm{R} 1=0.1153, \mathrm{RO}=0.3963, \mathrm{~L} 1=1.048 \mathrm{e}-3, \\
\mathrm{~L} 0=2.730 \mathrm{e}-3, \mathrm{C} 1=11.33 \mathrm{e}-9, \mathrm{CO}=5.338 \mathrm{e}-9\end{array}$ \\
\hline & & $\begin{array}{l}\mathrm{Km}=110, \mathrm{f}(\mathrm{Hz})=60, \mathrm{R} 1=0.01273, \mathrm{RO}=0.3864, \mathrm{~L} 1=0.9337 \mathrm{e}-3, \\
\mathrm{LO}=4.1264 \mathrm{e}-3, \mathrm{Cl}=12.74 \mathrm{e}-9, \mathrm{CO}=7.751 \mathrm{e}-9 .\end{array}$ \\
\hline & & $\begin{array}{l}\mathrm{Km}=220, \mathrm{f}(\mathrm{Hz})=60, \mathrm{R} 1=0.01165, \mathrm{R} 0=0.2676, \mathrm{~L} 1=0.8679 \mathrm{e}-3, \\
\mathrm{LO}=3.008 \mathrm{e}-3, \mathrm{Cl}=13.41 \mathrm{e}-9, \mathrm{CO}=78.57 \mathrm{e}-9 .\end{array}$ \\
\hline 4 & 3-ø Load (R Load) & $\operatorname{Vn}(\mathrm{Vrms})(\mathrm{KV})=500 \mathrm{e} 3, \mathrm{f}(\mathrm{Hz})=60, \mathrm{P}(\mathrm{KW})=30 \mathrm{e} 3$ \\
\hline 5 & $3-\varnothing$ (C Bank) & $\operatorname{Vn}(\mathrm{Vrms})(\mathrm{KV})=500 \mathrm{e} 3, \mathrm{f}(\mathrm{Hz})=60, \mathrm{Qc}=400 \mathrm{e} 3$ \\
\hline 6 & SSSC (Power Data) & $\begin{array}{l}\text { Vrms L-L }(\mathrm{Kv})=500 \mathrm{e} 3, \mathrm{f}(\mathrm{Hz})=60, \text { Snom }(\mathrm{MVA})=100 \mathrm{e}, \\
\mathrm{R}(\mathrm{pu})=0.16 / 30, \mathrm{~L}(\mathrm{pu})=0.16, \mathrm{Vdc}(\mathrm{Kv})=40 \mathrm{e}, \mathrm{C}(\mu \mathrm{F})=375 \mathrm{e}-6\end{array}$ \\
\hline 7 & $\begin{array}{l}\text { TCSC (Control } \\
\text { System) }\end{array}$ & $f(H z)=60$, Operating mode $=C$ \\
\hline 8 & TCSC (Firing Unit) & $\begin{array}{l}\mathrm{f}(\mathrm{Hz})=60, \mathrm{Ctcsc}(\mu \mathrm{F})=21.977 \mathrm{e}-6, \mathrm{Xtcsc}(\mathrm{H})=0.043 \\
\text { firing delay }=4 \mathrm{e}-3,\end{array}$ \\
\hline 9 & Timer & Time $(S)=[0,2,6]$, Amplitude $=[1.0,0.85,0.85]^{*} 128$ \\
\hline 11 & SVC (Power Data) & $\begin{array}{l}\text { Vrms L-L (Kv) }=500 \mathrm{e} 3, \mathrm{f}(\mathrm{Hz})=60, \mathrm{MVA}=200 \mathrm{e} 6, \mathrm{Qc}=200 \mathrm{e} 6, \\
\mathrm{Ql}=-200 \mathrm{e} 6, \mathrm{Td}(\mathrm{s})=4 \mathrm{e}-3\end{array}$ \\
\hline 12 & $\begin{array}{l}\text { SVC (Control } \\
\text { Parameter) }\end{array}$ & $\begin{array}{l}\operatorname{Vref}(p u)=1, \text { Droop }(p u / P b a s e)=0.03 \\
\operatorname{Vac} G \text { ains }[K p(p u B / p u V)=3, K i(p u B / p u V)=500]\end{array}$ \\
\hline
\end{tabular}

XIII. CONCLUSION

This paper has compared between the TCSC and SVC FACT device is presented and discussed. A Series capacitive compensation is thus used to reduce the series reactive impedance to minimize receiving end voltage variation and the possibility of voltage collapse and it can improve power flow capability of the line. In this paper, optimal placement and sizing of TCSC device has been proposed for improving and controlling the power flows in the network can help to increase the power flows in heavily loaded lines. A simulation result of MATLAB/SIMULINK model of a two-area four-machine 11-bus power system with a TCSC controller shows the effectiveness of TCSC in controlling active and reactive power through the transmission line. Hence, it is concluded that the results were obtained with TCSC and SVC device from the simulation, a proposed model of TCSC device is suitable for active, reactive power flow control and control the transmission line voltage is better as compared to SVC device.

\section{Acknowledgements}

I take this opportunity to express my profound gratitude and deep regards to my guide Mrs. Arti Bhandkkar Associate Professor S.R.I.T Jabalpur, for his guidance, monitoring and constant encouragement throughout the course of this thesis, She inspired us greatly to work in this thesis. The blessing, help and guidance given by him time to time. We also would like to thank her for showing us some example that related to the topic of our.

\section{REFERENCES}

[1]. Hatziadoniu C.J., Member, Funk A.K., "Development of a control scheme for a Series Connected Solid- State Synchronous Voltage Source" IEEE Transactions on Power Delivery.Vol. 11, No. 2, April, 1996.

[2]. K.R Padiyar FACTS Controllers in Power Transmission and Distribution

[3]. Edvina Uzunovic Claudio, A. Ca nizares John Reeve , EMTP Studies of UPFC Power Oscillation Damping North American Power Symposium (NAPS), San Luis Obispo, California, October 1999.

[4]. Vatsal J. Patel, C.B.Bhatt "Simulation and Analysis Real and Reactive Power Control with Series Type FACTS Controller" IJETAE, Volume 2, Issue 3, March 2012.

[5]. K.R Padiyar, "FACTS Controllers In Power Transmission Distribution", copyright 2007, New Age Internationa (P) Ltd., and Publishers.

[6]. N. Christl, P. Luelzberger, M. Pereira, K. Sadek, P. E.Krause, A. H. Montoya, D. R Torgerson, and B. A.Vossler, "Advanced Series Compensation with Variable Impedance", Proceedings of EPRI Conference on FACTS 1990.

[7]. R.Mohan Mathur, Rajiv K. Varma, "Thyristor based press,FACTS controllers for electrical transmission systems", IEEE 2002, A John Wiley \& Sons, INC. Publication.

[8]. MATLAB 7.12.0.635 (R2011a) Release notes Simpower System Toolbox_(Help).

[9]. Hasan Ghahramani, Akbar Lak, Murtaza Farsadi, Hossein Hosseini "Mitigation of SSR and LFO with TCSC based conventional damping controller optimized by PSO algorithm and fuzzy logic controller

[10]. N.G. Hingorani and L. Gyugi. Understanding FACTS concepts and technology of flexible AC transmission systems. IEEE Press, New York, 2000

[11]. Sidhartha Panda, Ramnarayan N. Patel "Improving Power System Transient Stability With An Off-Centre Location Of Shunt Facts Devices" JEE, VOL. 57, NO. 6, 2006, 365-368.

[12]. R. M. Mathur, R. K. Varma, "Thyristor-Based FACTS Controllers for Electrical Transmission Systems", Piscataway, NJ: IEEE Press, 2002. 